\title{
Analysis on Emotional Education Deficiency and Countermeasures of Students in Colleges and Universities
}

\author{
Lin Rong \\ China West Normal University \\ Nanchong, China \\ linronglinr@sina.com
}

\begin{abstract}
Colleges and universities are important stages for shaping and developing students' thinking ideology. They are cradles of human spiritual civilization. Colleges and universities are important periods of improving students' emotional intelligence. Acceptance of emotional education at stages has great role in promoting improvement of students' emotional education. Emotional education can actively guide students' behaviors, drive students to develop harmoniously and healthily in physical and mental aspects. Currently, China colleges and universities pay attention to imparting knowledge and skills, which are seriously lack of emotional education. Therefore, emotional education deficiency and countermeasures of students in colleges and universities are studied in the paper. Connotation and characteristics of emotional education in students of colleges and universities are analyzed. Current situation of emotional education deficiency of students in colleges and universities are analyzed. Emotional education development countermeasures of students in colleges and universities are proposed. In the paper, it is believed that emotional education is increased in classroom teaching, emotional connotation in campus culture can be enhanced, specialized emotional education courses are set up, and emotional experience and emotional improvement education are focused.
\end{abstract}

Keywords-students in colleges and universities; emotional education; deficiency; countermeasure.s

\section{INTRODUCTION}

Emotion is psychological experience produced by human objective desire, objective need and social existence. They are unique physiological phenomena of human beings. The positive emotion has promotion role on human beings. Negative emotion will bring bad effect to people. Colleges and universities create good education environment for emotional exchange between teachers and students. Good emotion is cultivated, thereby promoting more harmonious relationship between teachers and students, affecting students' learning, improving enthusiasm of learning, and improving teaching quality of colleges and universities. Emotional education requires that teachers in universities and colleges can explore students' psychological emotion sources, and appropriate methods and means are utilized for arousing students' positive and healthy psychological experience. The emotional education of teachers in colleges and universities refers that positive emotion can be utilized for infecting students, and allowing students to implement autonomous learning.

\section{CONNOTATION AND CHARACTERISTICS OF EMOTIONAL EDUCATION}

Emotional education refers to an education method that emotional experience of people can be triggered through emotional communication. Initiative of self-education of educatees can be stimulated. People are encouraged to convert correct recognition to conscious action on the mental basis of mutual trust and respect. Emotional education is a part of higher education process. It has very distinct characteristics: one is interest, interest of emotional education refers that learning interests of educatees can be stimulated through emotional education, therefore educatees can learn and participate in learning activities with interest according to own demand. Own interest quality can be cultivated and discovered in the process of learning and activity participation. Educatees can be driven for learning actively. The other is success. Success of emotional education refers that educators should create conditions in the emotional education process, and therefore educatees can obtain self-esteem and successful experience in the learning process, and constantly improve self-evaluation in the learning process. Positive self-evaluation should be established for promoting combination between educatees' personal value and social value. The third aspect is creativity. Emotional education is not provided with fixed and unified education mode. Educators should combine emotional education creativity for implementing education according to actual circumstance and individual differences of educatees. Emotional education can stimulate creation spirit of educatees, and educatees can be driven for autonomous learning and creative learning, thereby improving subjective initiative of educatees.

\section{ANALYSIS ON EMOTIONAL EDUCATION DEFICIENCY OF STUDENTS IN COLLEGES AND UNIVERSITIES}

\section{A. Classroom emotional education deficiency}

Classroom of colleges and universities is lack of emotional education. Educators and students have little communication in emotional education of colleges and universities at the 
aspect of education method. Currently, China colleges and universities focus on cultivating student's knowledge and practical ability, and strengthening students' competitive strength in market competition. The result is that college teachers pay attention to imparting knowledge to students during classroom education rather than attaching great importance to students' affective communication and thinking exchange. Fig. 1 shows that teachers in colleges and universities emphasize teaching purpose of developing students' ability and knowledge infusion in the teaching process. In addition, good learning method of students can be cultivated. Cultivation of student's emotional will only accounts for $7.1 \%$. It is obvious that teachers in colleges and universities are lack of students' emotional education. Fig. 2 shows that teachers in universities and colleges adopt lecture method as main teaching method in the classroom, and it belongs to unilateral infusion education. A few teachers adopt questioning method and discussion method. Therefore, teachers and students have less interaction in classroom between teachers and students. Teachers implement less education on student emotion. Fig. 3 shows that teachers and students in colleges and universities have less exchange. Most students and teachers have infrequent exchange. Only $19.9 \%$ students and teachers can exchange frequently, thereby leading to emotional education deficiency.

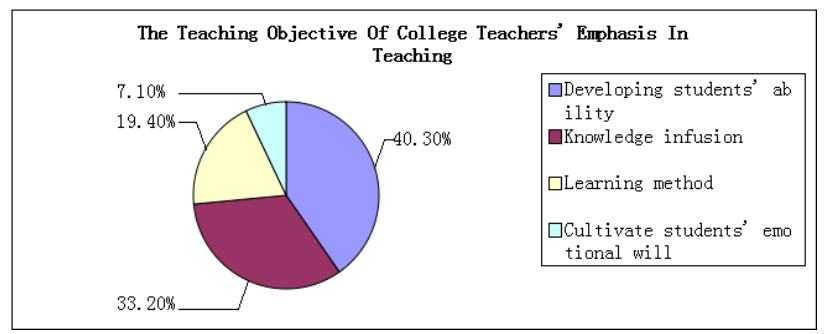

Fig. 1. Teaching purpose emphasized by college and university teachers in teaching

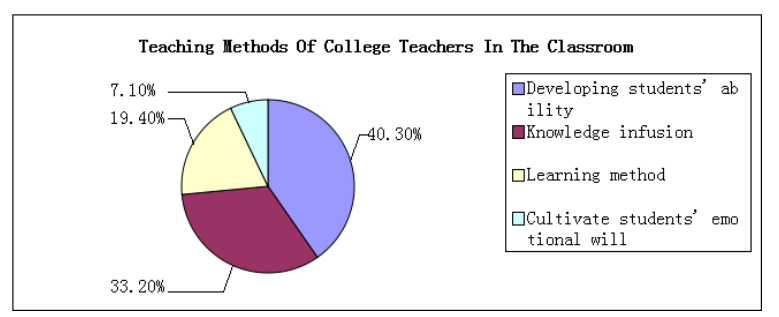

Fig. 2. Teaching method adopted by university and college teachers in classroom

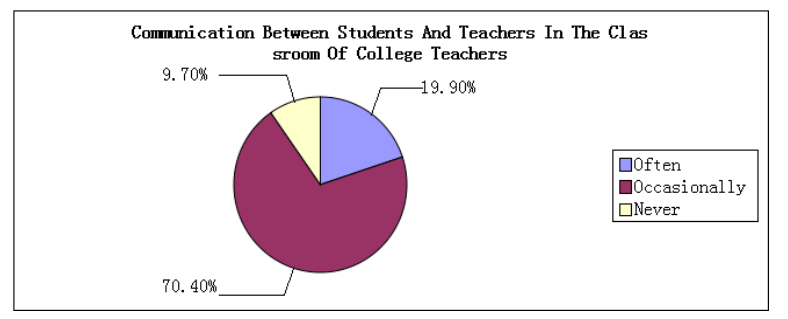

Fig. 3. Exchange condition between teachers and students in colleges and universities at classroom

\section{B. Emotional education deficiency of campus culture}

Campus culture is an important part of colleges and universities. It is important embodiment of school spiritual civilization and material civilization. College students' ideological connotation can be discovered, which has great impact on college students. However, many colleges and universities in China are seriously lack of campus culture emotional education currently. Colleges and universities fail in regarding campus culture as important carrier of emotional education. Less importance is attached to students' emotional education. Emotional element and emotional education are not embodied in campus culture. In addition, students in colleges and universities fail in recognizing importance of emotional education on own development. Therefore, students in colleges and universities lose the chances of accepting emotional education from campus culture.

\section{Plan deficiency in student emotional education}

There was emotional education in ancient China. More importance is attached to emotional education. Emotional education is developed to certain extent in modern times. However, there is greater dispute in all circles of society on objectives, methods, contents, connotation and other aspects of students' emotional education at universities and colleges currently. College teachers do not list emotional education into teaching plan. Emotional education is lack of scientific and complete teaching system. Emotional education is in a broken state. Colleges and universities fail in setting up substantive emotional education courses mainly because emotional education is a kind of recessive education. It is difficult to quickly create economic value. Spiritual value and humanistic care are reflected more frequently. Therefore, all colleges and universities do not attach enough importance to emotional education. In addition, emotional education belongs to an education thought of spirit and emotion without acceptance in a very wide range. Most emotion education in China colleges and universities lies in substantial education rather than practical education. Emotional education process is equivalent to a process of comprehending emotional education concept and accepting theoretical knowledge of emotional education. Therefore, only emotional recognition is increased in emotional education, which is lack of practical action. Emotional education can be obtained in practice activity. Emotional education in colleges and universities are lack of plan without physical existence. It is opposite to actual and direct feeling and experience of students in colleges and universities, thereby seriously limiting emotional education development of students in colleges and universities.

\section{COUNTERMEASURES OF EMOTIONAL EDUCATION FOR STUDENTS IN COLLEGES AND UNIVERSITIES}

\section{A. Increasing emotional education in classroom teaching}

Curriculum is the key for students to achieve education goal. Classroom is lack of carrier for students to reach education goal. College teachers should establish harmonious and democrat relationship between teachers and students and create good classroom environment during classroom teaching process. Loose and harmonious teaching atmosphere can be 
created, thereby promoting teachers and students to achieve more emotional exchange at classroom, and implementing emotional education. For example, college teachers can penetrate aesthetic knowledge at the classroom in a targeted mode, thereby students can discover artistic belief in daily life, student's desire to pursue beauty can be stimulated and they can obtain more positive emotion embodiment so as to stimulate students' interest in learning. College teachers should combine emotion and theory in classroom, and input more love and emotion. They not only should impart knowledge to students at classroom, but also should create good emotional experience atmosphere at the classroom, thereby stimulating students to love in studying autonomously. In addition, teachers must be good at promoting knowledge impartment by emotion. Power function of emotion can be exerted aiming at school-weary phenomena of students, thereby enhancing interests of education contents and methods, improving teaching art, arising students' positive emotion experience, and converting school-weary phenomena into 'love in studying'. Loose and harmonious learning atmosphere and learning activities not only can promote students' cognitive development, but also can promote students' emotional development.

\section{B. Strengthening emotional connotation in campus culture}

Campus culture is the important embodiment of student spirit and culture of college students. Currently, campus culture is lack of emotional education in China colleges and universities. In the paper, it is believed that emotional connotation in campus culture should be enhanced aiming at the above problem. More emotional education can be applied in campus activity. Some emotional activities should be implemented. For example, colleges and universities can carry out and organize some students' group activities or related communication meetings about emotional education, and plan more activities with emotion theme. More emotional theme color can be given in campus activity. Students can be affected subtly by emotional education through the media of campus culture. Emotional education in universities and colleges can penetrate to all aspects of students for affecting students' spiritual world and daily life. College students' daily life and emotional life can be more guided through campus culture activity, and students can be promoted to improve themselves better and more rapidly through positive emotional education.

\section{Setting up special emotional education courses}

University and college life acts as a transition stage for students from physiology maturity to psychological maturity. The stage plays a very important role for students' emotion, personality, ideal and will, etc., which can even determine the subsequent development of students. Students begin to consider significance of life and living in the university and college period, and their independence is stronger and stronger. Students in the period have formed relatively complete behaviors and thinking. However, they are not mature enough and weak relatively in psychological aspect, and their understanding on life value, life ideal, social justice and other issues is greatly changed compared with previous understanding. Their feeling on society and life is also gradually enhanced, and they are more sensitive to acceptance of society, other people and the state, and afraid of setbacks. Phenomenon of anxiety can appear, and it is a period of integrating real self and ideal self aiming at the condition. In the paper, it is believed that special emotional education course can be set up according to college students' psychological characteristics aiming at the situation. Special emotional education courses can be set up in colleges and universities, such as setup of emotional education courses in the aspects of family view education, love view education, view friendship education, success sense education, frustration sense education, honor sense education, etc. Therefore, students in universities and colleges can comprehend and control emotion more deeply, and recognition on emotion can be deepened. Their recognition on success and setbacks is more comprehensive and correct, thereby inspiring college students to cultivate positive emotions, and increasing loft depth, intellectuality and stability of college students of college students, and bringing more positive influence to students.

\section{Paying attention to education of emotional experience and emotional improvement}

Emotional embodiment can make students of colleges and universities involve in emotional situations. Students can emotionally and psychologically collide and feel family emotion, friendship and love, and they can understand the true meaning of life, understand life, and feel beat and greatness of life, thereby improving students' psychological quality, and stimulating students' positive emotions. Students of colleges and universities experience emotion in many forms. Some emotional films simulating reality can be manually set, thereby students can feel like realistic situation, and obtain some emotional inspirations from the situation. Students can be organized for watching some moving films. Beneficial emotion of students can be triggered by impact of visual effect as well as intuitive three-dimensional story plot; or students can challenge themselves, and rise up in the setback, thereby gradually building up confidence and courage to overcome difficulties. Students can directly enter the society and enter into the nature, thereby experiencing beauty of life and world. Emotional embodiment can promote students to obtain healthier and more positive emotional education, enrich students' personal quality, and guide students to improve individual joys and sorrows to collective and national sensibility. Students' sense of mission and sense of responsibility to the society can be improved, thereby assisting students to form nobler emotional world, more determined will, opener mind and sounder emotional world. Students in colleges and universities can be comprehended, satisfied, guided and sublimated in emotional education. Emotional distillation is the higher level of emotional education in colleges and universities, thereby reaching very positive promotion role to students' life and spiritual world

\section{SUMMARY}

Emotional education of college students should be cultivated and implemented on students through various approaches in campus life. Inspiration and guidance modes are adopted to create good emotional education atmosphere. 
Students can learn to study autonomously. They can manage and educate themselves. Positive emotional world can be formed. In the paper, it is believed that emotional education should be increased in classroom teaching aiming at students in contemporary colleges and universities. Emotional connotation in campus culture can be enhanced. Special emotional education courses are setup, and emotional experience and emotional improvement education can be focused.

\section{REFERENCES}

[1] Wang Xuhong. "Thinking on cultivating student faith character through emotional education," Journal of Anqing Normal College (Social Science Edition), 2012 , vol. 4, pp. 34-35.(In Chinese)

[2] Feng Ying. "On position and role of emotional education in ideological and political education," Management and Technology of Small and Medium-sized Enterprise (First-ten Day Edition). 2011, vol. 9, pp. 77-78 (In Chinese)
[3] Zhang Ying. "On education target and realization approach of college students' emotional education," Chinese and Foreign Entrepreneurs. 2011, vol. 2, pp. 21-22. (In Chinese)

[4] Guan Shuang. "Thinking on strengthening emotional education in colleges and universities," Heilongjiang Science and Technology Information. 2010 , vol. 21, pp. 126-127. (In Chinese)

[5] Wang Lingli. "Trouble and countermeasure of emotional education for students in universities and colleges," Law and Society. 2010, vol. 18, pp. 99-100. (In Chinese)

[6] Wang Yan. "Research on implementing emotional education," Journal of Liaoning University of Science and Technology, 2010 , vol. 1, pp. 1417. (In Chinese)

[7] Zheng Linchuan, Diao Yongfeng. "Research on value of emotional education in network ideological and political education," China West Science and Technology, 2010 , vol. 9, pp. 145-146. (In Chinese)

[8] Huang He. "My opinion on college students' emotional education," Journal of University Counselors. 2011 , vol. 1, pp. 52-54. (In Chinese)

[9] Liu Lei. "Emotional education 'stress analysis'-enlightenment of college student party member individual case," Theory Learning. 2013, vol. 11, pp. 63-64. (In Chinese) 